\section{Discussion}

The twins described in this case had no radiologic evidence of a congenital anomaly, despite exhaustive testing. The fact that the cardiac rhythms were synchronous was cause for concern, because synchronous heart rhythms in thoracopagus twins have been shown to be consistent with shared cardiac chambers. ${ }^{2,3}$ An electrocardiogram demonstrating independent QRS complexes suggests isolated ventricles. We could not find any case in the literature where there was an isolated myocardial bridge that could be separated.

Although the ability of individual myocytes to sustain an electrical potential and go through the cardiac cycle has been well described, the ability of shared myocardial tissue to propagate a rhythm between two individual hearts has not. The potential for heart block or other fatal arrhythmias was entertained, because we could not predict the electrophysiologic consequences of separating this tissue. Since the operation, the children have shown no cardiac abnormalities and have remained in sinus rhythm.

\section{References}

1. Patel R, Fox K, Dawson J, Taylor JF, Graham GR. Cardiovascular anomalies in thoracopagus twins and the importance of preoperative cardiac evaluation. Br Heart J. 1977;39:1254-8.

2. Sanders SP, Chin AJ, Parness IA, Benacerraf B, Greene MF, Epstein $\mathrm{MF}$, et al. Prenatal diagnosis of congenital heart defects in thoracoabdominally conjoined twins. $N$ Engl J Med. 1985;313:370-4.

3. Wu MH, Lai YC, Lo HM, Hsu YH, Lue HC. Assessment of electromyocardial continuity in conjoined (thoracopagus) twins. Am J Cardiol. 1992;69:830-2.

\title{
Thoracoscopic removal of a knife impaled in the chest
}

\author{
Joshua H. Burack, MD, Emmanuel A. Amulraj, MD, Patricia O'Neill, MD, Gregory Brevetti, MD, and \\ Robert C. Lowery, MD, Brooklyn, NY
}

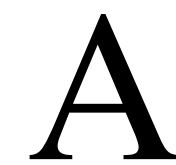

s surgeons become more comfortable with the technique, video-assisted thoracoscopic surgery (VATS) has evolved to provide both diagnostic and therapeutic value in increasingly complex cases of thoracic trauma. We report a case in which VATS techniques were used to remove a large knife impaled in the left side of the chest and to manage a concomitant injury to the left lower lobe of the lung.

\section{Clinical Summary}

A 25-year-old man was involved in an altercation and sustained a single stab wound to the left paraspinous region, midway between the tip of the scapula and the spine. The knife remained in situ, with only a large handle visible (Figure 1). The patient was transported by ambulance in the prone position and had stable vital signs on arrival to the emergency department. Examination was remarkable only for slightly decreased breath sounds on the left side, and the patient continued to have stable cardiopulmonary function. A chest radiograph confirmed the intrathoracic position of the knife at the seventh thoracic vertebra (Figure 2).

\footnotetext{
From the Department of Surgery, Chest Surgical Service, Kings County Hospital Center, Brooklyn, NY.

Received for publication April 19, 2005; accepted for publication May 20, 2005.

Address for reprints: Joshua Burack, MD, Department of Surgery, Box 40, State University of New York-Downstate, 450 Clarkson Ave, Brooklyn, NY 11203 (E-mail: jburack@ downstate.edu).

J Thorac Cardiovasc Surg 2005;130:1213-4

$0022-5223 / \$ 30.00$

Copyright $\odot 2005$ by The American Association for Thoracic Surgery doi:10.1016/j.jtcvs.2005.05.050
}

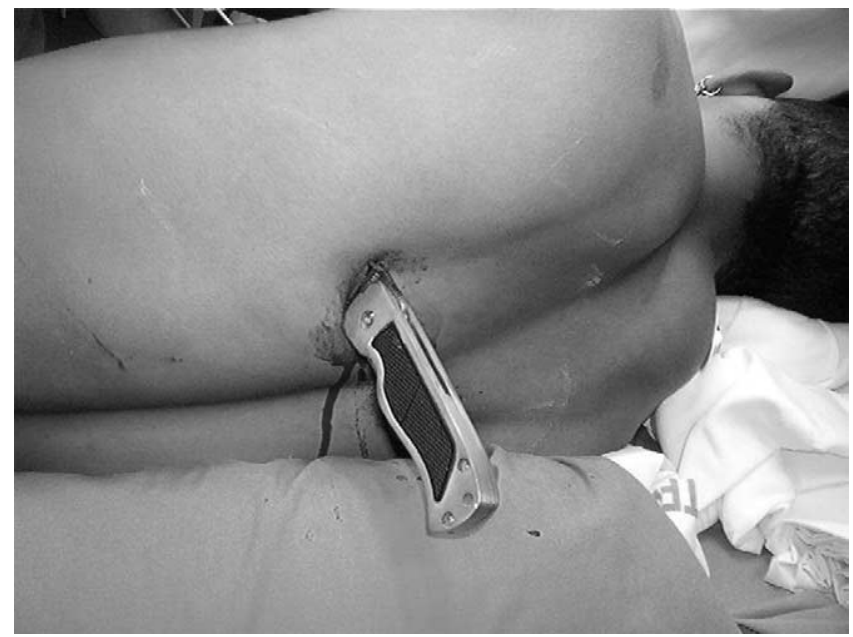

Figure 1. Large knife impaled in the posterior left chest.

Sixty minutes after the injury, the patient was anesthetized in the operating room with a double-lumen endotracheal tube. With the patient in the right lateral decubitus position, three separate 2 -cm thoracoscopic incisions were created in the left side of the chest: two in the fifth intercostal space and the anterior and posterior axillary lines and a third camera incision in the seventh intercostal space and the midaxillary line. On exploration, $700 \mathrm{~mL}$ of blood and clot was evacuated from the posterior pleural cavity, and no mediastinal hematoma was present. An 8-cm segment of knife blade was visible in the chest, just lateral to the middescending thoracic aorta, with a posterolateral tract toward the left lower lobe of the lung. A through-and-through injury of the 

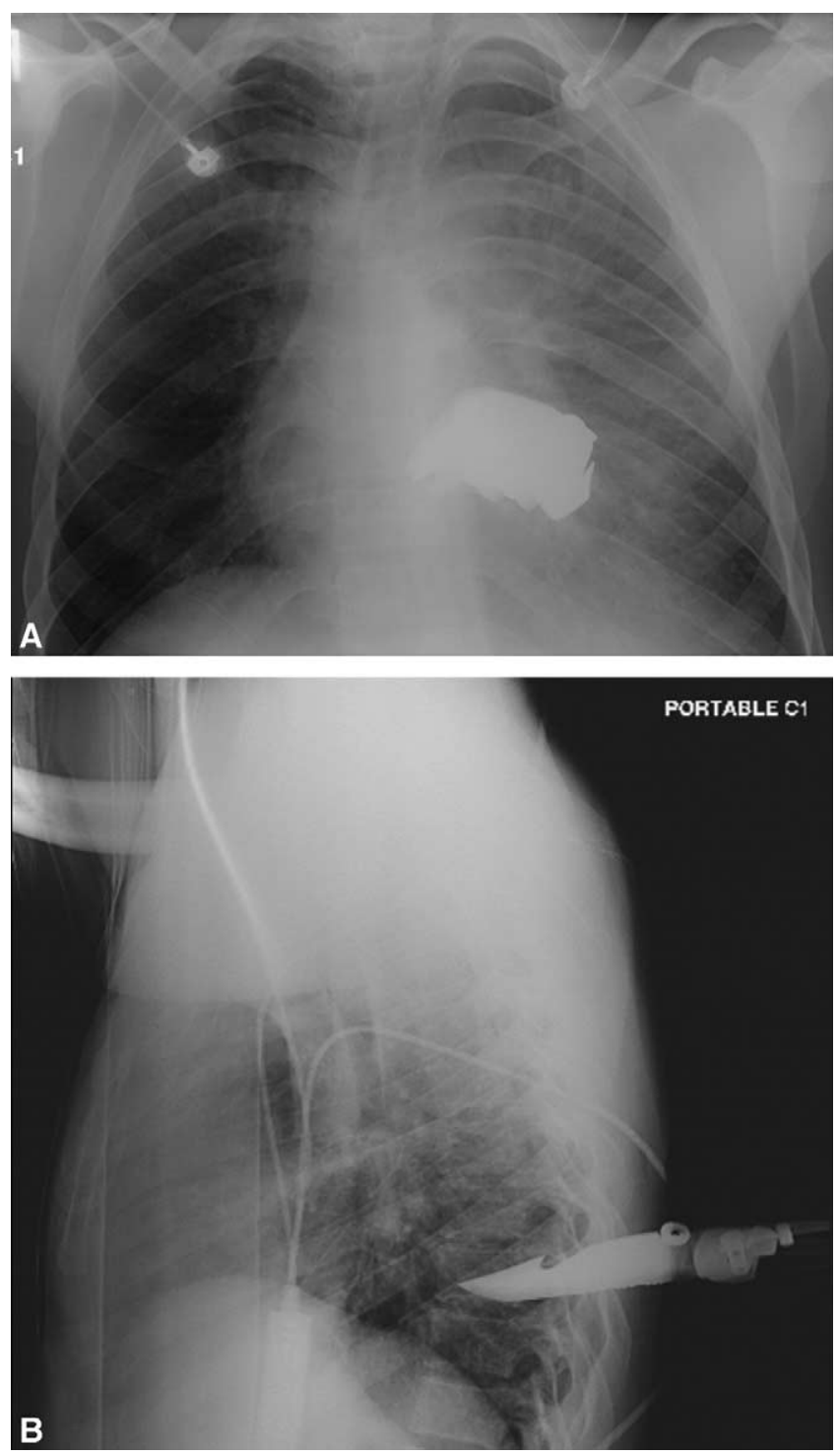

Figure 2. A, Posteroanterior chest radiograph. B, Lateral chest radiograph.

superior segment was visualized, with persistent, moderate hemorrhage from the lacerations. The knife was fixed in the chest wall because of the barbed nature of the blade, and it had to be gently manipulated and rotated clockwise away from the nearby aorta and then slowly removed. After removal, there was no significant bleeding from the chest wall. The pulmonary lacerations were managed with a wedge resection of the superior segment performed with several applications of an endoscopic linear stapler (Endo GIA 45; United States Surgical Corporation, Norwalk, Conn). A single chest tube was placed, and the patient was extu- bated in the operating room. The tube remained for 2 postoperative days and was then removed before hospital discharge. The patient was seen in follow-up clinic at 6 weeks and had no complications.

\section{Discussion}

Open thoracotomy has been the standard approach for the safe removal of an object impaled in the chest. A wide incision gives the surgeon excellent exposure and allows removal of the object under direct vision, as well as expeditious repair of associated vascular or visceral injuries. ${ }^{1,2}$ Several cases of successful thoracoscopic removal of retained intrathoracic bullets or fragments of glass and metal have been reported. ${ }^{3-5}$ In our case, these previously reported techniques were applied to a more complex situation with an associated active lung injury and an impaled knife, which was impacted into the chest wall. The videoscopic manipulation of knife blade, which was in close proximity to the aorta, was an invaluable adjunct in this case.

An alternative approach to the patient in stable condition with an impalement injury is to initiate an exhaustive radiographic evaluation, which can include a computed tomographic scan, an angiogram, and an esophagogram. After this workup is complete, the surgeon is still faced with the removal of the impaled object, which for reasons of patient comfort, sterility, and safety should be performed in the operating room. A well-planned VATS procedure, with the possible addition of endoscopic examination of the airway or esophagus, would preclude the need for an extensive preoperative evaluation.

In the case of a major vascular or cardiac injury, extreme caution with the current technique is advised. The VATS technique would be contraindicated for a patient in unstable condition. As was reported in this case, a patient with an intermediate vascular injury of the chest wall or lung may be managed with this technique. However, if a substantial hematoma were to be noted in proximity to a great vessel, the prudent maneuver would be early conversion to a thoracotomy. Finally, compared with an exploratory thoracotomy, the VATS techniques afford a minimally invasive approach with reduced postoperative morbidity and a typically brief hospital stay. VATS techniques should be carefully applied to an increasing number of complex trauma cases.

\section{References}

1. Cartwright AJ, Taams KO, Unsworth-White MJ, Mahmmod N, Murphy PM. Suicidal nonfatal impalement injury of the thorax. Ann Thorac Surg. 2001;72:1364-6.

2. Tsuei MK, Riley RD, Oaks TE, Chang MC. Mediastinal impalement with survival: a case report. Am Surg. 2001;67:594-6.

3. Manlulu AV, Lee TW, Thung KH, Wong R, Yim AP. Current indications and results of VATS in the evaluation and management of hemodynamically stable thoracic injuries. Eur J Cardiothorac Surg. 2004; 25:1048-53

4. Lang-Lazdunski L, Mouroux J, Pons F, Grosdidier G, Martinod E, Elkaim D, et al. Role of videothoracoscopy in chest trauma. Ann Thorac Surg. 1997;63:327-33.

5. Bartek JP, Grasch A, Hazelrigg SR. Thoracoscopic retrieval of foreign bodies after penetrating chest trauma. Ann Thorac Surg. 1997; 63:1783-5. 